\title{
A Mechanized Circulation System
}

A system is described in which embossed identification cards with machine readable numbers and embossed book cards are used to create an IBM charge card. The borrower's data is automatically punched into the card using an Addressograph 9500 Optical Code Reader. Other data is keypunched manually, and overdue notices are prepared by computer. Cards for selected groups of borrowers can be sorted out and reinserted in the files by machine.

M UCH HAS BEEN WRITTEN regarding systems design, stressing the need for total planning and for careful consideration of equipment, so that the best and most appropriate machines can be utilized to serve the library's purposes. Unfortunately, the library is not always in a position where it is permitted to make the decisions regarding machines, and it must therefore sometimes be able to adapt its requirements to suit the devices available. The system described here is one which was developed within such parameters; it might not have been formulated in this manner, nor using these machines, had the total systems approach been possible.

\section{BACKGROUND}

The library being described houses a collection of seventy-two thousand volumes, of which forty-seven thousand are bound journals and twenty-five thousand are monographs. Approximately fifteen hundred and fifty serial publications are currently received. The eligible borrowing population numbers two thousand and some thirty-nine thousand items

Mr. Pizer is Director of the Library and Assistant Professor of Medical History, at the State University of New York, Upstate Medical Center, Syracuse, New York. This paper was read at the 3d Symposium on Machine Methods, Washington University School of Medicine, April 8. are circulated annually. Approximately twenty-five hundred charge cards are in the files at a given time. The informational requirements of the circulation section necessitate that each volume be identifiable quickly as to name of borrower and location. Overdue materials in demand must be recallable, and records for departing users must be cleared at the end of each academic year. Items which are missing or at the bindery must also be traceable.

Since 1950 the library has used the Gaylord Charging System which calls for the issuance to each borrower of a card with a metal plate and the use of a special charging machine which imprints the number, together with the date due on a white $3 \times 5^{\prime \prime}$ book card. A major disadvantage of this system is the sole use of a number on the charge (book) card, since a register of borrowers must be consulted each time information is requested as to who has an item, or when overdue notices are sent.

With the opening of a new 370-bed teaching hospital, and the move to the medical center of the Syracuse Free Dispensary (now the hospital's outpatient department), accounting systems were designed to handle a large volume of transactions, and the equipment chosen to perform these tasks included an Addressograph Class 9500 Optical Code Reader and an IBM 1440 computer. 
TABLE 1

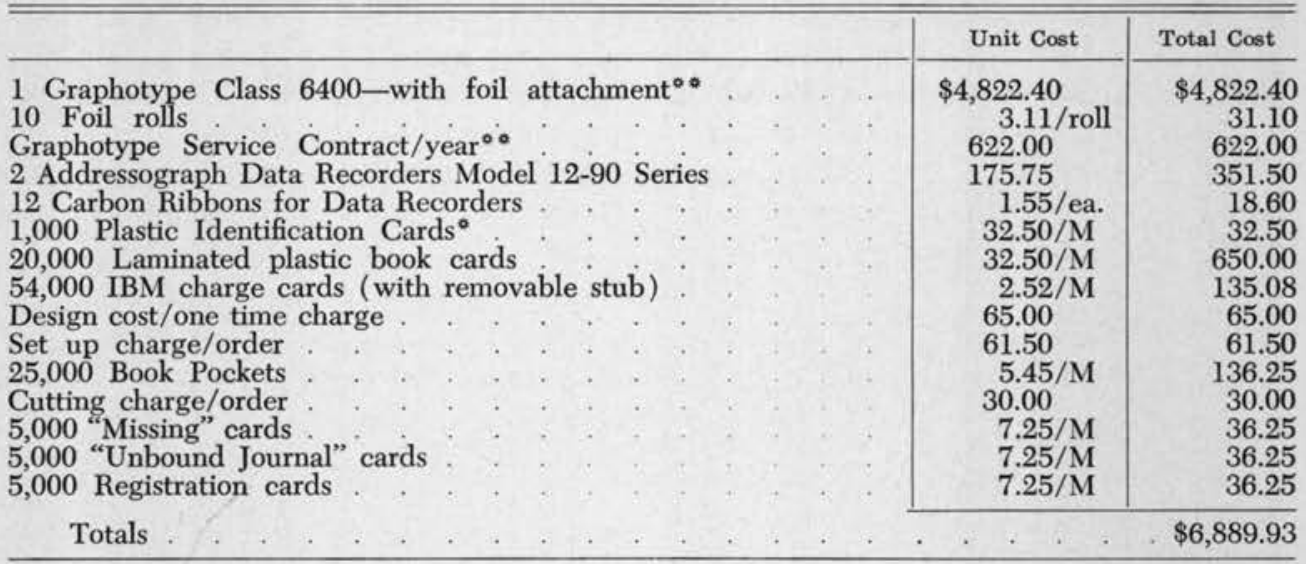

* Not charged to the library

** Cost shared with other departments

When a further decision was made to issue plastic identification cards to all members of the medical center (faculty, staff, students), the library was asked whether it could use such an ID card for a charging system. Since a somewhat similar system had been evolved by the author at the Washington University school of medicine ${ }^{1}$ and had proven itself workable, planning was begun on adapting that system to make use of the newer machines available and to exploit their capabilities.

The major conversion problem encountered by adopting an Addressograph system is the preparation of individual plastic book cards for all library materials. Cards do not have to be prepared immediately for all volumes in the library, however, since a considerable number of them do not circulate with regularity. Statistics have shown that approximately 85 per cent of the loans in a medical library are from the literature of the last five years, and it is these volumes which must be prepared first. The total number of book cards which must be made prior to operating

\footnotetext{
${ }^{1}$ I. H. Pizer, I. T. Anderson, and E. Brodman, "Mechanization of Library Procedures in the MediumSized Medical Library: II. Circulation Records." Bulletin of the Medical Library Association, LII (April 1964), 370-85.
}

the system is thus reduced to approximately 20,000 , based on acquisition figures for the last five year period. In order to identify the volumes which were to be handled, one copy of the book card was filed at the desk when an item circulated. This was possible only because the library had used a two card circulation system (one file arranged by author or journal title, and another file arranged by date due) until March 1964 .

The library was freed from the task of preparing cards for most borrowers since the ID cards would henceforth be issued by another office. It is important to note that the number assigned to each person was developed in conjunction with the library so that its needs would be met. The only ID cards for which the library is responsible are those for non-medical-center borrowers (professional community, Syracuse University faculty, etc.).

\section{EQUIPMENT AND SUPPLIES}

In order to operate the system the following materials are required.

\section{Borrower's Card and Data}

The borrower's card (Fig. 1) contains the name and address of the user, together with the designation student, fac- 
ulty, or staff, whichever is applicable. Residents and interns receive student cards. In order to make the three cards visually distinctive the headings are in different colors (red-student; orangefaculty; green-staff). A total of four lines of data may be recorded on each card. In addition a ten digit number is embossed across the top of the card in numeric and bar code form. This number, the bar codes of which are machine readable by the Optical Code Reader, identifies the borrower by category, school, year of graduation, or department. The faculty number was developed using the library's existing faculty numbers in order to lessen confusion, because materials charged out to faculty tend to remain out for longer periods, and therefore old charges could be more

Fig. 1-The borrower's card contains four lines of address data, and a code number which is recorded in numeric and bar code form (these are not visible because they are not stamped with colored foil).

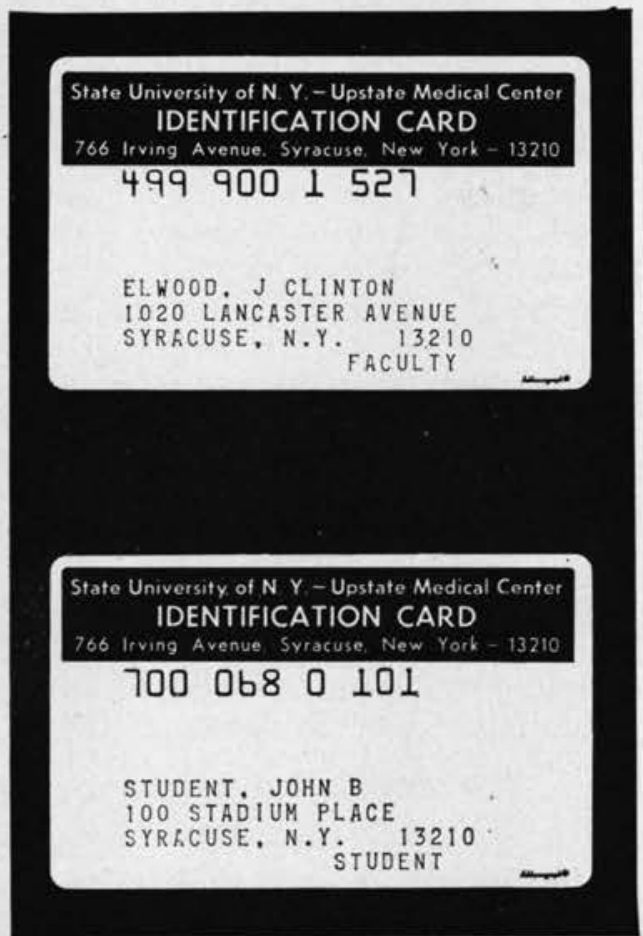

simply traced. A departmental code number was added to the former number. This enables the library to machine search the circulation files for the charges of any particular group of borrowers, e.g., graduating students, departing interns, etc.

\section{BOOK CARD}

The plastic card prepared for each volume is also limited to four lines of data (Fig. 2). For books, line 1 is reserved for author, lines 2 and 3 for title, and line 4 for call number and accession number. (No accession records are maintained by the library but a control number is assigned to each book as it is processed, and this number appears on the shelf list card. It obviates the need for copy designation, speeds discharging of books when returned, and is invaluable in inventory for positive identification of volumes.)

\section{Charge Card}

This is a specially designed IBM card (Fig. 3) which serves to identify imprinted data, and to outline the card fields for keypunching of book and journal information (see Table 2). The cards are color coded along the 12-edge so that charges which come due in a particular week are easily found. The center portion of the card is printed as a reserverecall form which is filled out by the requesting user and then replaced in the file after being clipped to indicate the reserve request.

\section{Adpitional Cards}

Registration. In order to maintain a file of active borrowers, when an ID card is presented at the circulation desk for the first time, the plate is imprinted on an IBM card (Fig. 3a) which specifies that the user will abide by the library's regulations. The borrower is asked to sign a statement indicating his responsibility for all loans made on his card and to provide his phone number. 
Nonbook materials. To charge out items which do not have plastic book cards (unbound journals, pamphlets, etc.) the borrower's imprint is recorded on an IBM card (Fig. 3a) and the required information is written in by the user. These cards are not keypunched.

Missing materials. When an item is declared to be missing, /an IBM card (Fig. 3a) is prepared and placed in the appropriate file. These cards may be keypunched.

It should be noted that the three "additional cards," while conforming to standard punched card size, etc., have been manufactured for the library by Gaylord Bros. This step was taken for several reasons. Because a relatively small number of these cards would be used each year, it was felt that the set-up and design charges of $\$ 126.50$ per card would be excessive. The large quantity of cards that would have to be ordered to make the price per card economically practical would cause long term storage problems, and on reorders, there would still be a set-up charge of $\$ 61.50$.

TABLE 2

\begin{tabular}{|c|c|c|c|}
\hline Columns & & & Data \\
\hline \multicolumn{4}{|l|}{ Books } \\
\hline 1 & . & . & Book Code \\
\hline $2-11$ & . & . & . Borrower's number \\
\hline $12-17$ & . & & Date Due \\
\hline $18-35$ & & & . Author's Last Name \\
\hline $36-65$ & . & & . Book Title \\
\hline $66-67$ & & & . Volume \\
\hline $68-69$ & & & . Edition \\
\hline 70 . & & & . Copy \\
\hline $71-74$ & & & . Year \\
\hline $75-80$ & . & . & . Cutter Number \\
\hline \multicolumn{4}{|l|}{ Journals } \\
\hline 1 & & & Blank \\
\hline $2-11$ & & & . Borrower's Number \\
\hline $12-17$ & . & & Date Due \\
\hline $18-62$ & & & Journal Title \\
\hline $63-67$ & & & Volume \\
\hline $69-70$ & & & Part \\
\hline $71-74$ & & . & Year \\
\hline $75-80$ & & . & . Blank \\
\hline
\end{tabular}

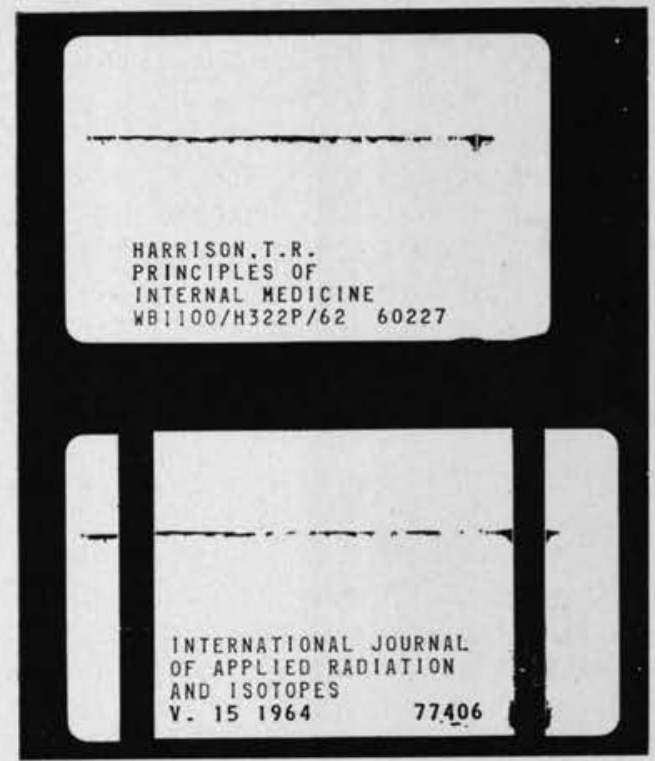

FIG. 2-The plastic cards for insertion in the bound volume also contains four lines of descriptive data as shown. The book cards are scored along the sides so that the flaps can be broken off to make them fit the Data Recorder. The advantage to having them full size for the Graphotype operation is that only one style holder need be used and accurate alignment in embossing is assured.

\section{Conversion Period}

During the months between October 1964 and September 1965, when the system is scheduled to begin operation, processing of books must suit both charging systems. In order to do this, the plastic book card is prepared and is then used to imprint both the old and the new book pockets, and one book card (Fig. 4).

It is expected that the addressograph system will be started for faculty charges by June, whenever possible, in order to cut down the number of old faculty charges which will have to be handled in the fall.

\section{Charging Procedure}

The method of charging materials is quite simple. The borrower produces his ID card as he presents the materials de- 


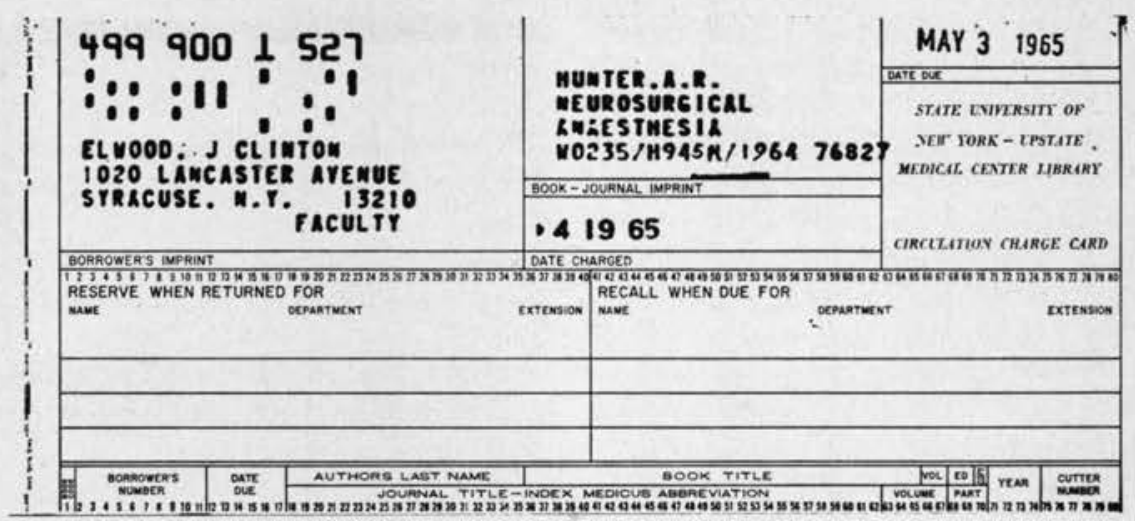

Fig. 3-Shown here is a dummy of the charge card to be used. There is a removable tab on the left side which is used to align the card in the Data Recorder. It is removed when the information has been imprinted on the card.

sired at the circulation desk. Both the ID card and the plastic book card are inserted in the Data Recorder (Fig. 5) and an IBM card is placed on top of the cards. The machine is closed and a handle is pulled across the face of the cards, thus bringing a carbon ribbon in contact with the embossed data and imprinting it on the IBM card. The Data Recorder also imprints the date charged. The book card is returned to the pocket together with an appropriate date due card, and the ID card is returned to the borrower.

After the charge card has been prepared, it is kept in a file of the day's circulation in sequence by author or journal title. A statistical count is made at the end of the day, and the following morning the pertinent data is keypunched into the cards.

Each morning a supply of date due cards is pre-stamped in a quantity estimated to last the day.

\section{Mechanics}

Each morning the cards for the previous day's circulation of between 100 and 200 bound volumes are taken to the data processing department, where they are first run through the Optical Code Reader (Fig. 6). This procedure is done in two steps, first for journals, and then for books. The machine automatically punches the borrower's number into columns 2-11 of the IBM card by reading the bar codes. The reader has the ability to punch up to 40 columns of numerical data into a card, and using this capability, a code number 9 is

Fig. 3a-The three specially printed circulation forms are shown here (reduced). They are printed on different colored card stocks in order to lessen confusion and to guard against the forms being accidentally used for the wrong purpose.

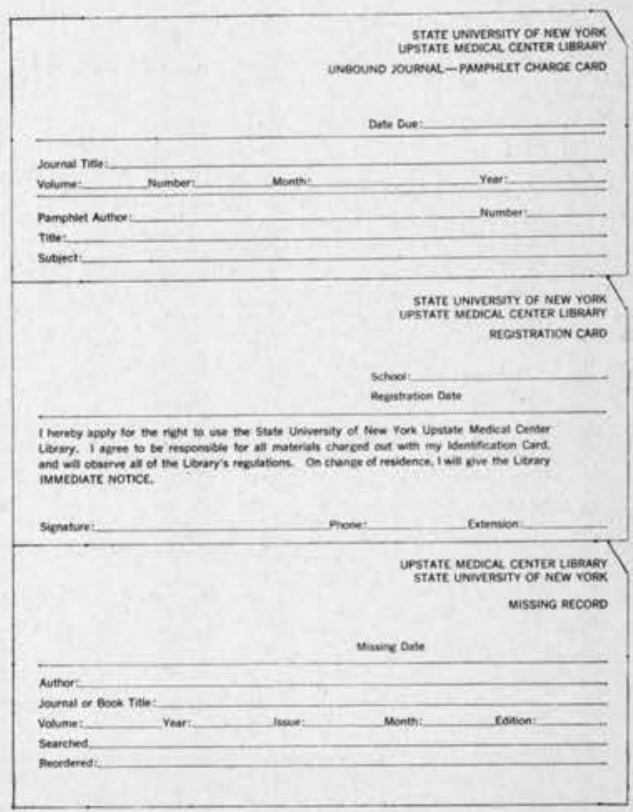


punched into all the book cards in column 1 , so that book and journal cards may be machine separated, and the date due is punched into columns 12-17.

After this step is completed the cards are manually keypunched with the appropriate book or journal data needed to identify the particular item. The cards are then returned to the library where they are manually filed.

Because the charge cards are not easily reproducible, errors in keypunching must be corrected with self-adhesive patches on the original card and then * repunched.

When a book is returned, the keypunched charge card is pulled from the files and inserted into the book pocket after being marked "void." The next

Fig. 4-The plastic book card (lower right) is used to print the book pocket and card for the Gaylord system, and a book pocket in which it is housed. time that volume circulates, the borrower's data and volume data are imprinted on a new charge card, and the old charge card is removed from the book pocket and placed with the new charge card. Since the book and borrower's data is automatically punched into the card and the keypunched data from the old charge can be duplicated into the new one rapidly, all keypunching is eliminated on such transactions. Washington University school of medicine library has found, on the basis of one year's experience, that over 60 per cent of the items charged out of the library have old cards, and it may be expected that this figure will rise somewhat over a longer period of time.

\section{Overdue Notices}

In order to send overdue notices, the circulation files are sorted according to school, year, and department. (Overdue

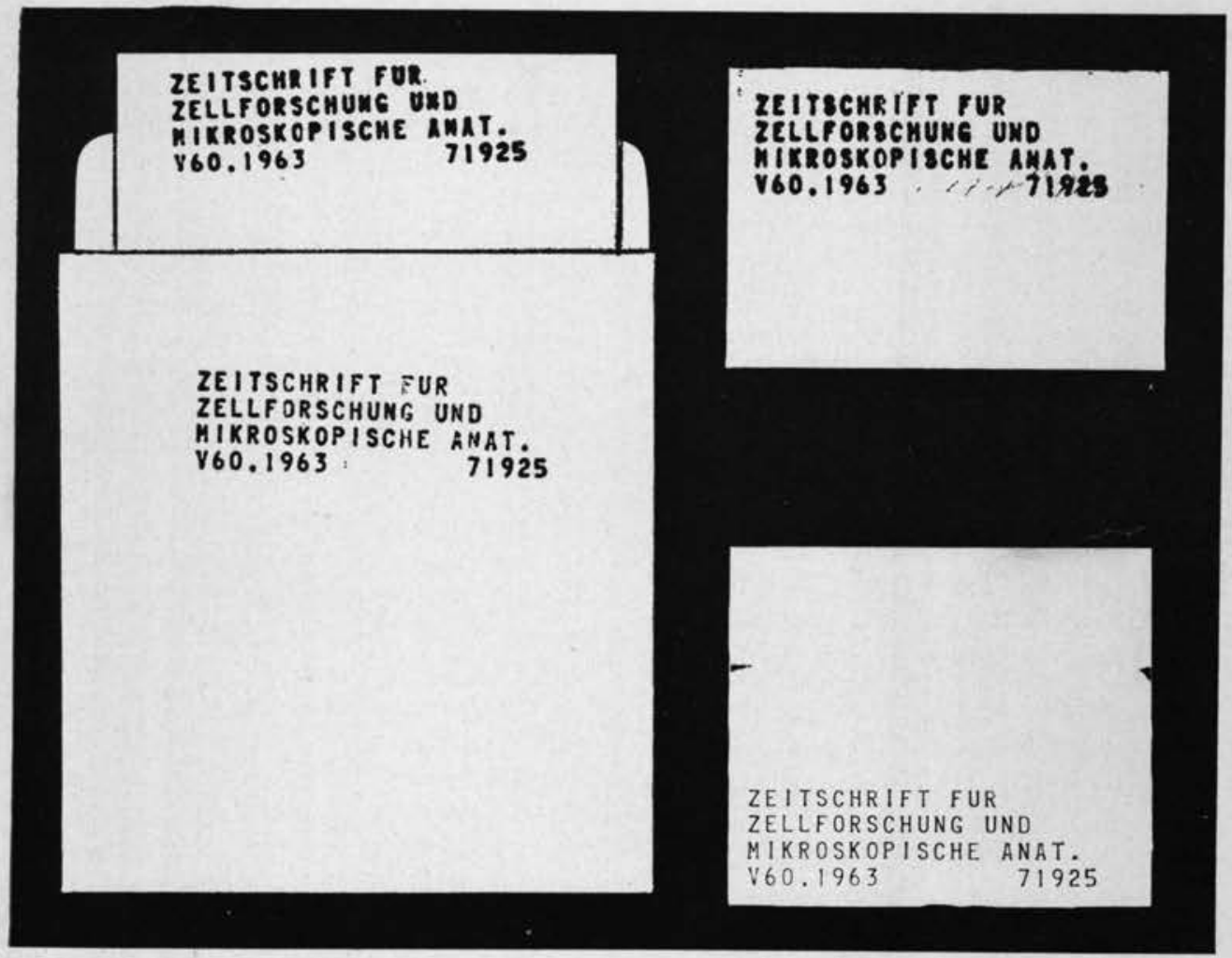


notices are not sent to faculty unless a book is needed by another reader.) The cards are then inserted in an IBM collator which matches them against the name and address cards, inserting the address card before each group of charges. When the deck has been collated, it is run into the 1440 computer which is programed to print out the name and address in block form (Fig. 7), print a legend stating that the following items are overdue, and list all items for the borrower. When the computer compares numbers on the entering cards and find that they are not identical, the forms are advanced to a new page and the next overdue notice prepared.

The stack of forms is then sent to the library, where the sheets are inserted in window envelopes and distributed either by mail or campus delivery.

It is quite likely that when the system becomes operational, the entire file will be reproduced on a duplicate deck, instead of sorting the circulation file into various number sequences. This pro-

Fic. 5-The Data Recorder is shown here with a book card already in place (on right) and an ID card being inserted. The carbon ribbon is visible through the step-shaped cutout in the hinged top section. The ribbon is advanced each time the top section is opened. The date charged is printed by a group of six number wheels situated below the book card.

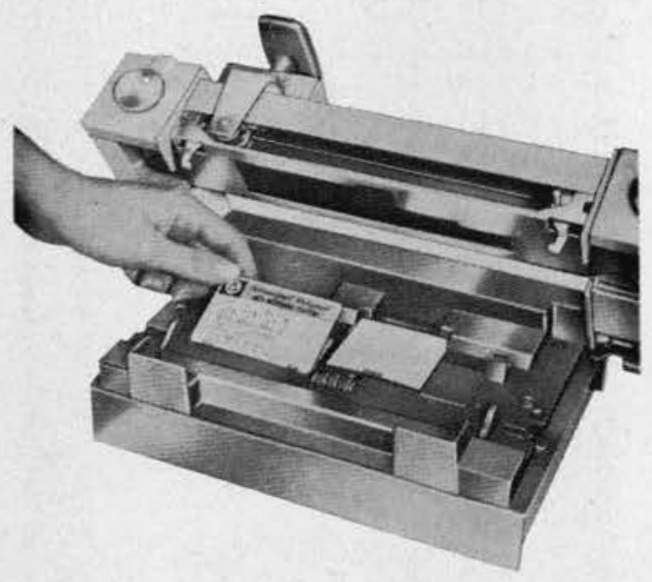

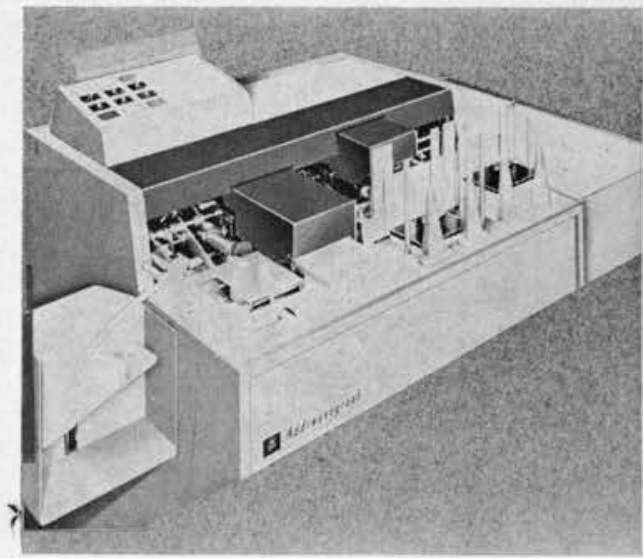

FIG. 6-The 9,500 Optical Code Reader is used to automatically punch the borrower's number in the card, and at the same time punch the date due and a code to distinguish books from journals. Two feed hoppers are shown, but the hopper on the left is the one used for this procedure. The data to be punched into each card, other than the bar coded number, is set on the small panel to the left of the feed hopper. The completed cards are ejected and stacked on the bin at the left. The machine's functional controls are located on the panel on the top of the unit.

cedure will obviate the need for disarranging the master file and enable it to be returned to the circulation desk in a matter of hours, while all procedures relating to rearrangement of the file for overdue notices are performed on the duplicate deck. The latter would then be discarded after the overdue notices have been printed. ${ }^{2}$

\section{Conclusion}

It can be seen that this system is basically the same as the one at the Washington University school of medicine, except that some changes have been made in equipment. The Graphotype coats the embossed letters with a colored foil when the card is completed in order to facilitate reading; newly designed data recorders are used which print with a carbon ribbon, necessary for sensing

2 E. A. Moore, and E. Brodman, "Communieation to the Editor." Ibid. LIII (January 1965), 99-101. 


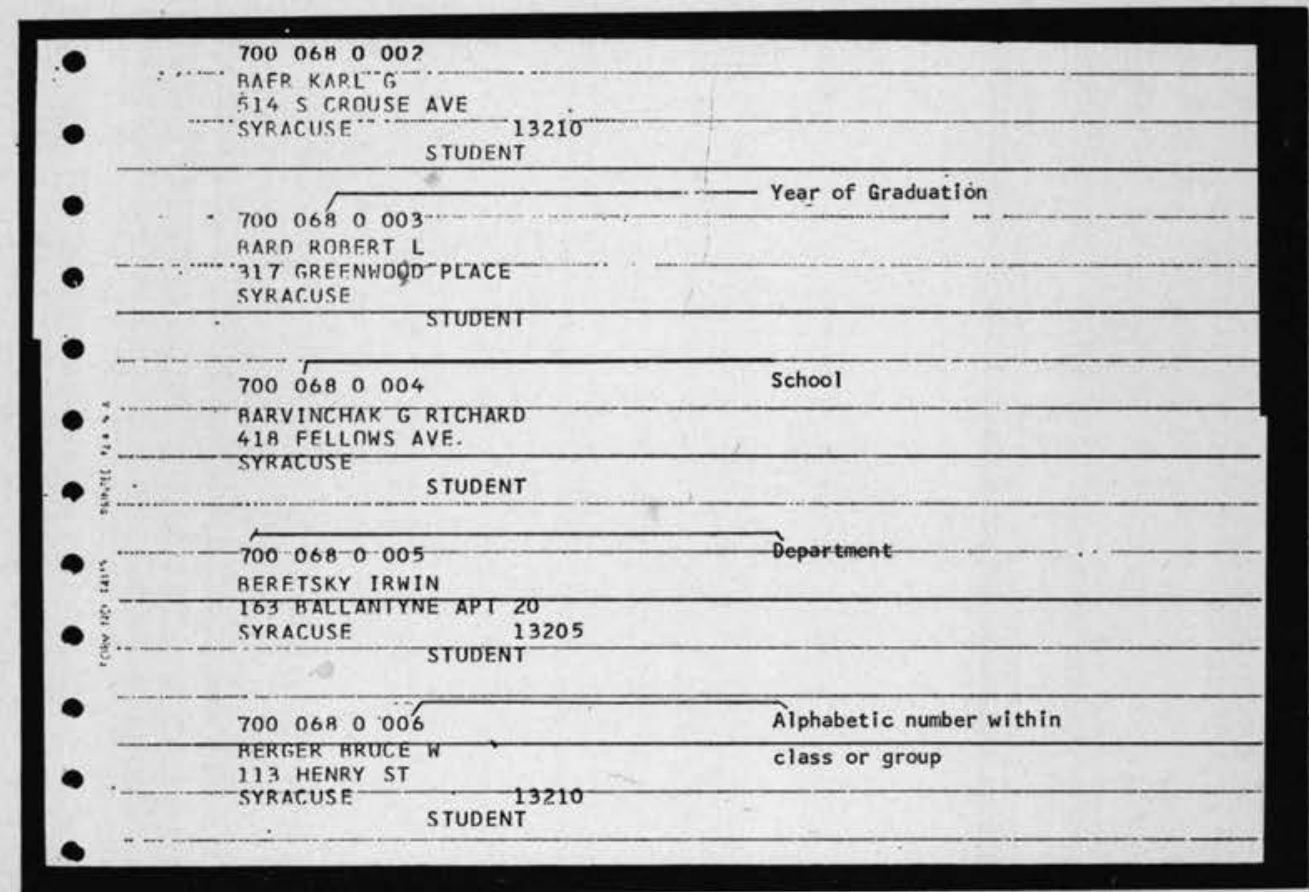

FIG. 7-Printout showing the address blocks and numbers as they appear on the ID cards. The 10-digit number is broken down as shown. The division of the number into groups of three digits is purely arbitrary and done to make Graphotyping of the card easier.

by the Optical Code Reader; and the Optical Code Reader is used to insert automatically seventeen columns of numeric data into the charge cards in order to cut down on the keypunching.

Because different imprinting machines were available, the charge card is oriented in one direction which makes it easier to read and to keypunch. The use of a machine codable number positioned at the left side of the card frees additional columns for data recording, and allows larger fields to be assigned to author and book titles, the brevity of which caused some slight problems in the first system.

It may be noted that this is not an especially cheap method of circulation control; however, not all of the costs listed in Table 1 are charged to the library and the major cost of the Graphotype and its service contract are divided between the various departments which use it.

Given the limitations of already selected machines, this system does provide a neat and workable solution to a circulation problem. The time' of the Circulation Staff which is eliminated in producing the overdues is not gained, however, but merely reassigned to keypunching the daily circulation. 